\title{
An Emergent Approach to the Guttural Natural Class*
}

\author{
John Sylak-Glassman \\ University of California, Berkeley
}

\section{Introduction}

The post-velar consonants, including the uvulars, pharyngeals/epiglottals, and glottals, have been argued to form the guttural natural class. ${ }^{1}$ This natural class is claimed to be part of humans' innate knowledge of language (McCarthy, 1994:203). For this to be a meaningful claim, it must make predictions that are borne out by typological evidence. One prediction is that many, if not most, languages with post-velar consonants will show overt evidence of the existence of the guttural natural class. A further prediction is that no matter which post-velar consonants occur in a language, there should be an equal likelihood of finding evidence for the guttural natural class. However, typological data indicates that this is not the case. Languages with pharyngeal/epiglottal consonants are more likely to show evidence for the guttural natural class than languages that lack these consonants but possess other post-velar consonants (such as uvulars and glottals). This paper seeks to show that phonetic properties of the pharyngeal consonants allow them to pull other consonants into phonologically patterning with them in a way that other post-velars, especially glottals, do not. These phonological patterns provide evidence that can be used by speakers to construct a phonologically active class.

First, $\S 2$ discusses claims made about the guttural natural class and the predictions of proposing that it is innate. In $\S 3$, typological evidence is presented to show that the presence of pharyngeals in a given language enhances the likelihood of finding sound patterns in that language that provide evidence for the existence of the guttural natural class. Next, $\S 4$ discusses the means by which other post-velar segments (uvulars and glottals) can be pulled into phonologically patterning with the pharyngeals. It is shown that this phonological association can occur both because of articulatory factors and through post-velar consonants affecting vowels in a similar way. Section $\S 5$ presents a preliminary derivation of the effects of post-velars on vowels using similarity scales, and $\S 6$ offers a brief conclusion.

\section{Background and Predictions: The Guttural Natural Class}

Hayward \& Hayward (1989) and McCarthy $(1991,1994)$ argue that the post-velar consonants, which include the uvulars, pharyngeals, and glottals, form a universal guttural natural class. In Semitic and Cushitic languages, various phonological processes and distributional constraints require reference to the post-velar consonants as a phonologically active class. A phonologically active class is "[a] group of sounds in an inventory which do at least one of the following, to the exclusion of all other sounds in the inventory: undergo a phonological process, trigger a phonological process, or exemplify a static distributional relation" (Mielke, 2008:13). One example of some post-velar consonants behaving as a phonologically active class by exhibiting a static distributional relation occurs in Arabic. Root co-occurrence constraints prohibit consonants of the same place of articulation from co-occurring in a root, and the uvular fricatives, pharyngeals, and glottals cannot occur together (McCarthy, 1994:204). Another example, in which post-velars trigger a phonological

*Thank you to Sharon Inkelas, Keith Johnson, Andrew Garrett, and Florian Lionnet for helpful advice and discussion of this work. This work has also benefitted from discussion with John McCarthy, Jonah Katz, and others at Phonology 2013. I am also grateful to the US Department of Education and the UC Berkeley Graduate Division for support.

${ }^{1}$ The pharyngeal and epiglottal places of articulation are not phonologically contrastive. Despite the claim by Ladefoged \& Maddieson (1996) that Agul (Nakh-Daghestanian) contrasts these places of articulation, the data can be better analyzed in articulatory terms as a distinction in manner (Moisik 2013:119-138, Esling 1997:8-9, Heap 1997:1819). Hereafter, 'pharyngeals' should be interpreted as referring to both pharyngeals and epiglottals (as symbolized in the IPA).

(C) 2014 John Sylak-Glassman

Proceedings of Phonology 2013

Completed February 14, 2014 
process, comes from Standard Somali (Cushitic), in which certain nominal and verbal suffixes have /-t/ and /-d/ alternants, and the "/-d/ alternants occur with stem-final vowels, glides, and gutturals (/q, $\chi, \mathrm{f}, \mathrm{h}, \mathrm{P}$, h/)" (Hayward \& Hayward, 1989:184). The most common evidence for the guttural natural class comes from sound patterns in which vowels are categorically lowered (often to /a/) adjacent to a triggering postvelar consonant. Such processes occur in Arabic, Maltese, Tiberian Hebrew, Tigrinya (all Semitic), and D'opaasunte (Cushitic; Hayward \& Hayward 1989; McCarthy 1994), among others.

While the Semitic and Cushitic languages cited in Hayward \& Hayward (1989) and McCarthy (1994) provide strong evidence for the guttural natural class, the claim that the guttural natural class is a part of speakers' innate knowledge of language (McCarthy, 1994:203) has faced two main challenges. ${ }^{2}$ First, the composition of phonologically active classes that include post-velar consonants appears to vary even among languages with similar inventories. While in many cases, the phonologically active classes are subsets of the proposed guttural natural class (e.g. faucals in Interior Salish languages; cf. Rose 1996), some are supersets (e.g. in Jaqaru, the uvulars, /t', k'/, and/r/ lower /u/ to [o]; Hardman 1983:43-44). Second, no single acoustic characteristic or active articulator appears to unite all the segments that can belong to the guttural natural class, which is a problem for feature systems that are based on these phonetic characteristics. Instead, the guttural natural class must be defined on the basis of a zone of passive articulation, which is what Hayward \& Hayward (1989) and McCarthy (1994) advocate.

In some languages, uvulars and glottals demonstrably do not pattern with the other post-velars in phonologically active classes as would be expected under the hypothesis of a universal guttural natural class. While the uvular fricatives $/ \chi /$ and $/ \mathrm{s} /$ are considered to be part of the guttural natural class in Arabic, the uvular stop /q/ is considered not to be guttural (McCarthy, 1994:202-203). Instead, it is grouped both with the dorsal consonants (namely $/ \mathrm{k} /$ and $/ \mathrm{g} /$ ) and with the emphatic (i.e. pharyngealized) consonants, reflecting the idea that the phoneme /q/ is better understood as $/ \mathrm{k}^{\mathrm{I}} /$ (as argued in Jakobson 1962:515-518). Due to the absence of uvulars other than /q/ in Tiberian Hebrew, the gutturals in that language appear to include only pharyngeals and glottals, thereby excluding the uvular place of articulation as a whole. ${ }^{3}$ For the Interior Salish languages, Bessell (1992:312-315) argues that the gutturals in those languages, termed the 'faucals,' include uvulars and pharyngeals, but not glottals. ${ }^{4}$ Although uvulars or glottals sometimes appear to be excluded from the guttural natural class in a given language, pharyngeals are never excluded. That is, in any language with at least one pharyngeal consonant and any surface evidence for the guttural natural class, the pharyngeal consonant(s) will pattern as part of the guttural natural class.

Another challenge to the proposed innateness of the guttural natural class is the fact that it is not unified by an active articulator. Every more anterior consonant is grouped under an active articulator node (e.g. Labial, Coronal, Dorsal) in feature geometric models, which leads to the expectation that the gutturals should also be grouped under an active articulator node. However, the lack of a common articulator prevents this: Uvulars are articulated with the tongue dorsum, pharyngeals with the epilarynx and tongue root, and glottals with the glottis. To deal with this problem, Hayward \& Hayward (1989) and McCarthy (1994) propose that the gutturals are instead unified by being articulated in a broad zone of articulation that encompasses the entire lower vocal tract from the oropharynx to the glottis. Although this claim sparked research into the possible unifying phonetic characteristics of the guttural natural class (e.g. Goldstein 1994, Zawaydeh 2003), such a characteristic has remained elusive.

\footnotetext{
${ }^{2}$ The explicit claim by McCarthy (1994:203) that the guttural natural class must be part of speakers' innate knowledge comes in response to the possible challenge that it is an idiosyncratic part of Semitic and Cushitic phonology:

The notion "idiosyncratic property of a language family" makes sense only as a claim about language history. But a phonological rule referring to gutturals that is an innovation in a particular Semitic language cannot be inherited from the proto-language; in this case, appeal to a Semitic idiosyncrasy is purely mystical, since there is no mechanism by which language learners might discover this idiosyncrasy and apply it in a novel rule. The only sensible account is that the natural class of gutturals is already available to language learners from linguistic theory [emphasis mine]; they could not discover it from their Semitic heritage.

${ }^{3}$ If this /q/ is interpreted as underlying $/ \mathrm{k}^{\mathrm{S}} /$ (as in Arabic), then Tiberian Hebrew has no underlying uvular consonants.

${ }^{4}$ Rose (1996:87-89) argues that because an epenthetic vowel before / $/$ / surfaces as [a] rather than as [ə], the laryngeals as a whole have a lowering effect on vowels similar to uvulars and pharyngeals, rendering them phonologically guttural.
} 


\section{Presence of Pharyngeals Conditions Guttural Natural Class Effects}

If the guttural natural class does exist as part of humans' innate linguistic competence, it might be expected that evidence for the guttural natural class would be common in languages that have the requisite phonemes. Because the uvulars, pharyngeals, and glottals are all potentially guttural, it might also be expected that the types of post-velar phonemes that are present in a language's phonemic inventory should not influence whether evidence for the guttural natural class is apparent. That is, if a language has uvulars and glottals, but lacks pharyngeals, the uvulars and glottals should pattern together as gutturals just as often as each would pattern with pharyngeals.

To test the predictions of positing an innate guttural natural class that includes uvulars, pharyngeals, and glottals, this study queried P-base (Mielke, 2008), a database listing phonemic inventories, phonological processes, and distributional constraints from 628 language varieties. ${ }^{5}$ To find evidence of the guttural natural class, languages were surveyed for phonological processes or distributional constraints that referred to groupings which included exclusively post-velars as targets or triggers. ${ }^{6}$

To determine the contributions of consonants at each post-velar articulation to phonological processes in which multiple post-velar places of articulation are involved, languages with only a single post-velar place of articulation were surveyed for processes in which post-velar consonants caused changes in vowel quality, namely lowering and backing, that are attested with post-velar consonants that act as gutturals (as claimed in Hayward \& Hayward 1989 and McCarthy 1994). This helps to establish the extent to which independent effects of consonants at each post-velar place of articulation can be expected to contribute to phonological effects.

In querying P-base, 3 languages (23\%) of the 13 that have uvulars as their only post-velar consonants show lowering or backing effects on vowels. Only one language, Northern Talysh (Indo-European) was listed as containing a pharyngeal consonant, but no uvulars or glottals. ${ }^{7}$ However, no phonological effects of this consonant were noted for Northern Talysh in the database or the original source. Out of the 396 languages that have glottals as their only post-velar consonants, only one language, Amharic (Semitic), shows effects that suggest that glottals are guttural. Amharic's sole post-velar consonant, glottal $/ \mathrm{h} /$, usually neutralizes the vocalic opposition /ə/ vs. /e/ in favor of lower /e/. However, Hayward \& Hayward (1989:179-180, 190) show that these effects can be attributed entirely to the fact that most tokens of contemporary $/ \mathrm{h} /$ derive from a historical merger of $* \chi, * \hbar, * h>h$. Other tokens of $/ \mathrm{h} /$ in Amharic result from another sound change $(* k$ $>h$ ) in which $/ \mathrm{h} /$ does not originate from a post-velar consonant, and these tokens of $/ \mathrm{h} /$ do not neutralize the distinction between $/ \partial /$ and $/ \mathrm{e} /$. The results of surveying languages with post-velar consonants at only a single place of articulation are shown in Table 1.

\begin{tabular}{lccc} 
Place of Articulation & Uvular & Pharyngeal & Glottal \\
\hline Lowering/Backing Effects & $3(23 \%)$ & $0(0 \%)$ & $1(0.25 \%)$ \\
\hline No Effects on Vowels & 10 & 1 & 395 \\
\hline Total Languages & 13 & 1 & 396
\end{tabular}

Table 1: Lowering or backing effects by post-velars in languages with post-velar consonants at only one place of articulation.

Since the effects surveyed so far occur with consonants at only a single place of articulation, they cannot be attributed to a higher level phonological class (such as the gutturals) since the effects can be interpreted as characteristic of that particular place of articulation only. However, with two post-velar places of articulation, it allows for the possibility that sound patterns could refer to both places of articulation and

\footnotetext{
${ }^{5}$ This corresponds to approximately 549 distinct languages according to the divisions in Ethnologue (Lewis, 2009). Throughout this section, "languages" should be understood as referring to P-base language varieties.

${ }^{6}$ A majority, but not all, post-velars were required to participate in these processes for them to count as evidence of the guttural natural class. For example, a process in which uvulars and pharyngeals, but not glottals, cause vowel quality changes would be counted as evidence since the majority of post-velars participated in the process.

${ }^{7}$ The source used in P-base, Schulze (2000), is based on data from a single text given by one informant (5). The only description given of the consonant is its category label, 'pharyngeal,' and its transcription as " $h / h /$ " (9). This leaves the possibility that the consonant is actually glottal.
} 
thereby provide evidence for a higher level grouping like the guttural natural class. Because the guttural natural class encompasses three places of articulation, the prediction is that any two should have an equal likelihood of patterning together in the languages in which they occur.

However, this appears not to be the case. Of the 58 languages in P-base that contain uvulars and glottals but no pharyngeals, only 2 (3.44\%; Misantla Totonac and the Samish dialect of Straits Salish) show effects in which the two places of articulation pattern together. However, in languages with pharyngeals and at least one other post-velar place of articulation, there appears to be a greater likelihood that there will be evidence for the guttural natural class. Two of the 10 languages (20\%) with pharyngeals and glottals but no uvulars show evidence for the guttural natural class, and 3 of the 17 languages (17.65\%) with all three post-velar places of articulation show such evidence. This evidence suggests that in the absence of pharyngeal consonants, the guttural natural class is less likely to be observed.

Data from P-Base (Mielke 2008)

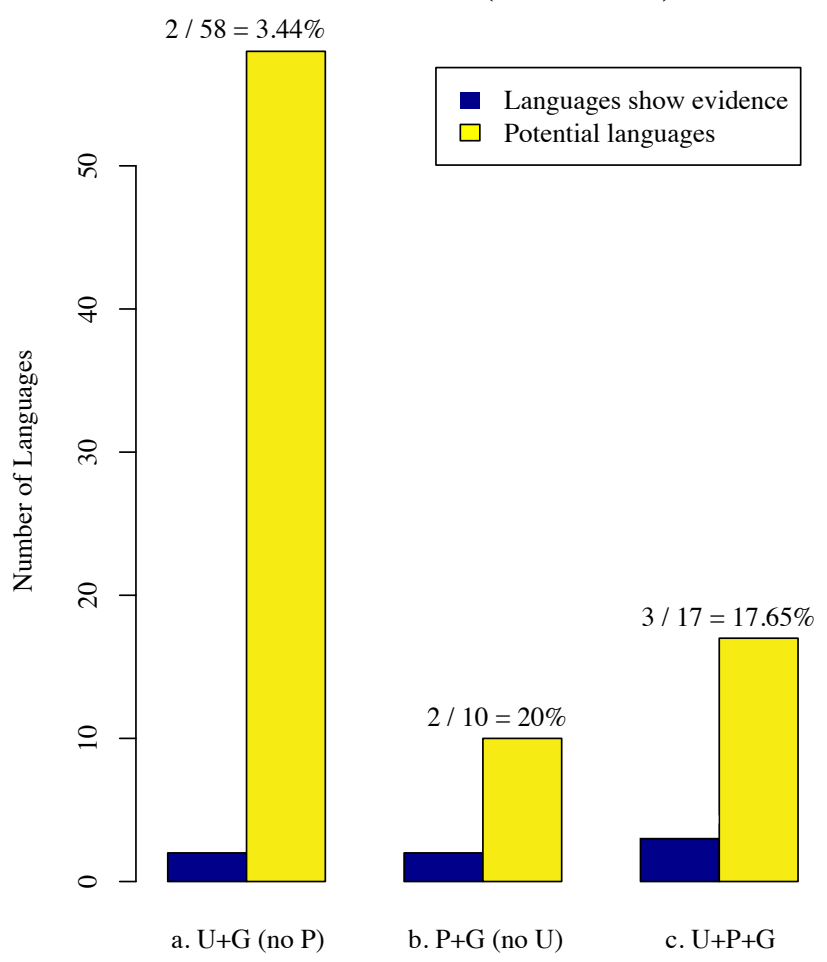

Figure 1: Languages with consonants at certain post-velar places of articulation, divided into those that show evidence for the guttural natural class (yellow) and those that do not (blue) based on evidence from P-Base. Mielke (2008)

Logistic regression analysis on the data in Figure 1 shows this to be true. The logistic regression analysis modeled the likelihood that languages with a particular combination of places of articulation would show evidence of the guttural natural class using the presence of each post-velar place of articulation as a main factor. Modeling the likelihood of a language showing evidence of the guttural natural class was done using the generalized linear model Likelihood $\sim$ Uvular*Pharyngeal*Glottal in $R$ (R Core Team, 2013), where each factor coded the presence or absence of that place of articulation. Because the factor Glottal never varied (i.e. glottal consonants were present in every combination), this factor was discarded from the analysis, yielding the model Likelihood Uvular*Pharyngeal. A stepwise evaluation of this model revealed that having a pharyngeal consonant (Pharyngeal) was a significant factor $(p<0.05)$. The results of an ANOVA using the $\chi^{2}$ test on the final model, Likelihood $\sim$ Pharyngeal*Uvular, are presented in Table 2. 


\begin{tabular}{lllllll} 
& DF & Deviance & Resid. DF & Resid. Dev. & $\mathrm{P}(>|\chi|)$ & \\
\hline NULL & & & 84 & 48.361 & & \\
Pharyngeal & 1 & 5.0870 & 83 & 43.274 & 0.02411 & $*$ \\
Uvular & 1 & 0.0229 & 82 & 43.251 & 0.87966 & \\
Phar:Uv & & 0 & 82 & 43.251 & &
\end{tabular}

Table 2: ANOVA using the $\chi^{2}$ test on the final model, Likelihood Pharyngeal*Uvular

These results support the idea that the presence of pharyngeals increases the likelihood of the appearance of evidence of the guttural natural class. From the results for single post-velar places of articulation, laid out in Table 1, one would not expect glottals to increase that likelihood, but it seems uvulars would have the potential to increase the likelihood of finding surface evidence for the guttural natural class. This does not seem to occur, though, since when only uvulars and glottals are present, the likelihood of finding evidence for the guttural natural class is very low.

It is unexpected that the presence of pharyngeal consonants would increase the likelihood of the appearance of surface evidence of the guttural natural class. If the guttural natural class is innate and includes all three post-velar places of articulation, the expectation is that if any two of the three places of articulation are present, sound patterns should be equally likely to reference those two places together. It may be contended that the uvulars' ability to pattern with the velars as dorsals and the glottals' ability to pattern independently may make them less likely to pattern phonologically as gutturals. However, if the guttural natural class is innate, the presence of two of the three places of articulation should increase the likelihood of the occurrence of phonological processes that refer to both, no matter the specific identity of the segments. The fact that this happens very rarely points to the special status of pharyngeals in providing surface evidence for the guttural natural class.

\section{Pharyngeal Association}

It is argued here that the reason that languages with pharyngeals are more likely to show evidence of the guttural natural class is that pharyngeals are able to pull other consonants into phonologically patterning with them for both articulatory and acoustic reasons. These articulatory and acoustic links cause uvulars and glottals to individually pattern with the pharyngeals.

4.1 Association by Articulation Pharyngeals are primarily articulated by constricting the epilarynx (Moisik, 2013). The epilarynx is "the set of structures comprising the ventricular folds, aryepiglottic folds, epiglottis, and arytenoid cartilage complex" (26), as shown in Figure 2. The epilarynx is nested within the larynx as a whole, and the larynx is positioned within the bottom part of the pharynx (23). The epilarynx can constrict sphincterally in two ways. Either intralaryngeal muscles can constrict it, or it can be constricted through the action of external muscles (13). This sphincteric constriction of the epilarynx is obligatory in articulating pharyngeals. Although tongue retraction often occurs in the articulation of pharyngeals, it is not obligatory. Tongue retraction facilitates epilaryngeal constriction and enhances pharyngeal articulations by helping to push the epiglottis back toward the posterior pharyngeal wall (ibid.; Esling 2005:26).

The epilarynx can be divided functionally into two halves, upper and lower (Moisik, 2013:25). The upper epilarynx includes the aryepiglottic folds and the epiglottis (ibid.). Because epilaryngeal constriction pulls the epiglottis back and tongue retraction achieves the same effect, tongue retraction can be understood as being synergistic specifically with upper epilaryngeal constriction (74-75). Under a view of the tongue as a hydrostat in which changes to one part affect all other parts (372-373), tongue retraction will have consequences for the tongue dorsum, which is the active articulator for uvular consonants. The synergistic relationship of epilaryngeal constriction and tongue retraction offers a possible articulatory path for uvulars and pharyngeals patterning together phonetically. The lower epilarynx includes the ventricle cavity and the ventricular folds (27). The ventricular folds can be brought down onto the vocal folds to help stabilize the articulation of the glottal stop (213-214). They couple with the vocal folds and are brought down onto the glottis to achieve the constriction necessary for creaky voice (ibid.) and they stabilize glottal closure for [?] $(218,385)$. This provides a straightforward articulatory pathway for interaction between pharyngeals and the 
a)

b)

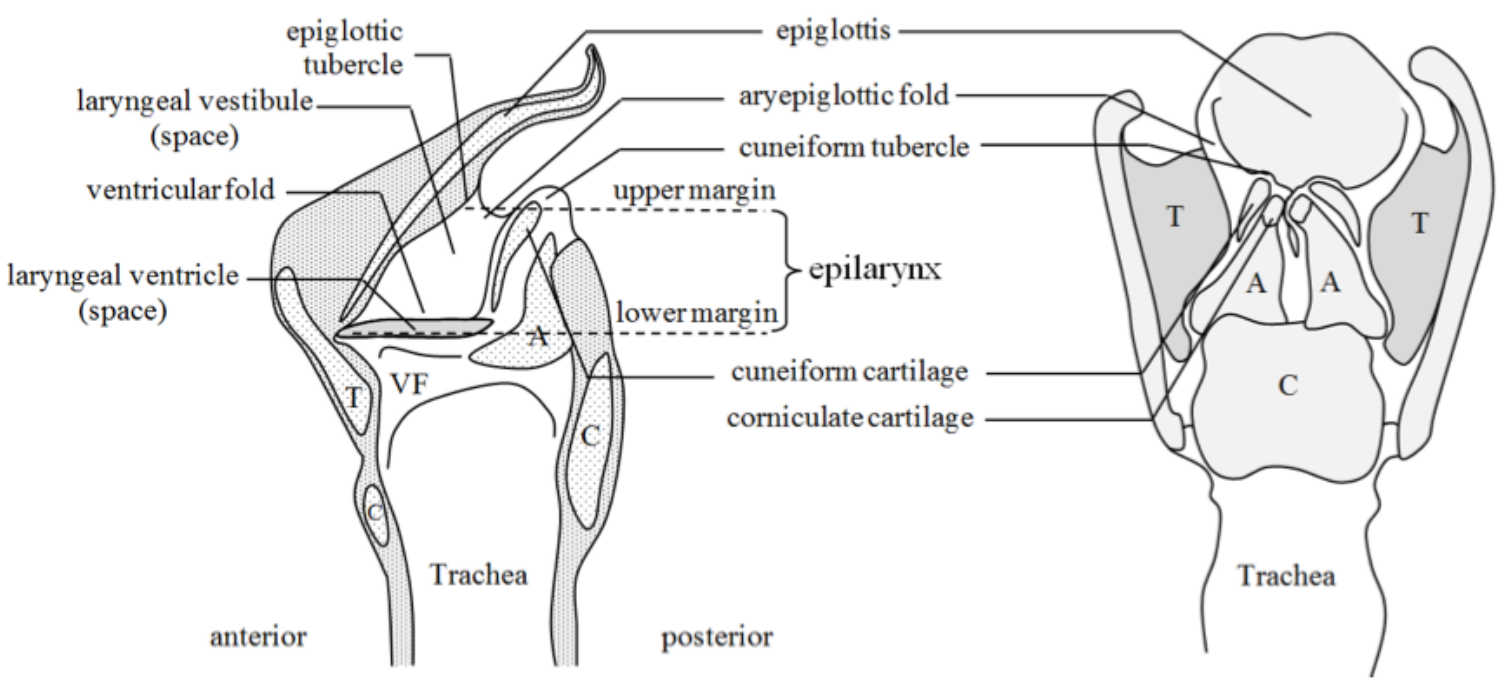

Figure 2: Figure 2.2 from Moisik (2013:20). Schematic view of the larynx illustrating structures of the epilarynx. The illustration on the left (a.) is a mid-sagittal section while the illustration on the right (b.) is the interior of the larynx from a posterior point of view. Abbreviations: $\mathrm{A}=$ arytenoid cartilage, $\mathrm{C}=\mathrm{cricoid}$ cartilage, $\mathrm{T}=$ thyroid cartilage, $\mathrm{VF}=$ vocal fold.

glottal stop. ${ }^{8}$ The phonetic patterning of uvulars and glottals with pharyngeals, facilitated by articulation, provides a path for phonological association to occur.

4.2 Association by Articulatory-Acoustic Interaction: Effects on Vowels When the post-velar consonants affect vowels as part of a post-velar phonological class (e.g. the guttural natural class), they seem to cause vowels to be articulated with a more open vocal tract configuration and more tongue retraction. Because these articulations actively facilitate the articulation of pharyngeal consonants (Moisik, 2013:13), they are phonetically associated with them. When pharyngeal consonants are present in a language, an open vocal tract configuration and tongue retraction can become phonologically associated with those consonants. Uvulars cause vowels (especially non-high) to become more retracted. The effects of uvulars on vowels are then phonologically associated with articulations for pharyngeal consonants, and this provides another pathway by which uvulars could begin to pattern phonologically with pharyngeals.

To understand how this happens, it is necessary to relate the articulation of consonants to vowels, which requires articulatory features for vowels. The standard phonological features for vowels $([ \pm \mathrm{high}],[ \pm$ low $]$, $[ \pm$ back]) were originally proposed as articulatory features, but are better interpreted as acoustic features such that height corresponds to F1 (with [+high] corresponding to low F1 and [+low] corresponding to high F1) and backness corresponds to F2 (with [+back] corresponding to low F2). Esling (2005) presents a new articulatory proposal for vowel articulation in which the vowel space can be divided into front, central, raised, and retracted vowels (see Figures 2, 4, and 5 in Esling 2005:19, 22-23). The front and central vowels are the traditional front and central vowels, but in Esling's model, the traditional back vowels are divided into raised ([o] and higher) and retracted ([0] and lower) vowels. The labels 'front,' 'raised,' and 'retracted' refer to

\footnotetext{
${ }^{8}$ This articulatory explanation seems to be the best one for accounting for why glottal stop would pattern with pharyngeals $(/ \mathrm{h} /$ is presumably associated with $/ \mathrm{P} /$ by virtue of their common articulator). No languages in P-base or Sylak-Glassman (in prep) seem to exhibit glottals independently causing formant-shifting effects on vowels. It is unlikely, then, that glottals have independent acoustic effects through which they could become associated with pharyngeals. Because the patterning of glottals with pharyngeals is most likely articulatory, the discussion in $\S 4.2$ focuses on interactions between uvulars and pharyngeals.
} 
"lingual movement [that is] attributable to the three major extrinsic lingual muscle groups: the genioglossus, the styloglossus, and the hyoglossus," respectively (ibid.). Another relevant parameter is the degree of vocal tract openness, which adds an articulatory vowel height distinction to the front vowels (Esling, 2005:18-19).

These parameters can be formalized into the binary features $[ \pm$ front $],[ \pm$ raised $],[ \pm$ retracted $]$, and [ \pm open]. ${ }^{9}$ These features do not replace the traditional (acoustic) vowel features, but supplement them. Because of their articulatory nature, they are better suited to processes in which production seems to be the best explanation. Similarly, they can be used to provide an interface between vowels and consonants since they refer to lingual positions, not vowel articulations per se. ${ }^{10}$ It is assumed that the representation of vowels can include both articulatory and acoustic features.

\begin{tabular}{|c|c|c|}
\hline$i^{\text {[-back] }}$ & $\begin{array}{r}\text { [+back] } \\
\text { u }\end{array}$ & [+high] \\
\hline $\mathrm{e}^{\mathrm{I}}$ & $\begin{array}{l}\text { U } \\
\quad\end{array}$ & $\begin{array}{l}{[\text {-high] }} \\
{[- \text { low }]}\end{array}$ \\
\hline$\varepsilon$ & 0 & \\
\hline $\begin{array}{l}æ \\
\mathrm{a}\end{array}$ & $a$ & {$[+$ low $]$} \\
\hline
\end{tabular}

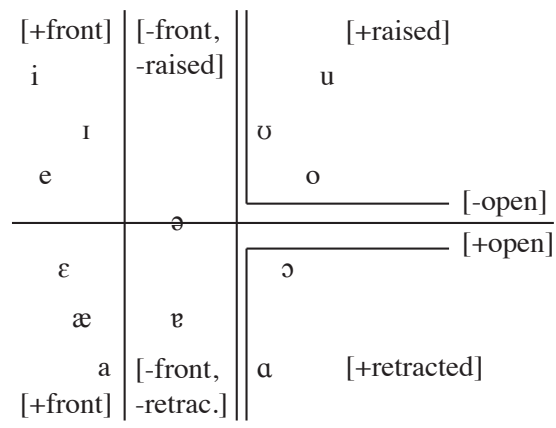

Figure 3: Vowel space divided according to traditional features (left) and according to the articulatory description in Esling 2005 (right)

In [+raised] vowels, the tongue is pulled not only up, but back. Uvular consonants are articulated with this tongue posture (Esling, 2005:31), although there are articulatory differences between uvular stops and fricatives. Uvular stops tend to involve the most raised articulation, while uvular fricatives have a more retracted articulation (Moisik, 2013:463-466, and p.c.). This provides a possible articulatory basis for the distinction between these sounds in Arabic, and also allows for the possibility that $/ \mathrm{u} /$ is most similar to uvular stops while a less raised vowel, such as /o/ or $/ \mho /$, may be most similar to uvular fricatives. Because all the raised vowels, $/ \mathrm{u}, v, \mathrm{o} /$, are similar to the most common types of uvulars, stops and fricatives, these are taken to be the most similar to uvulars as a whole. While pharyngeals need not be articulated with tongue retraction, tongue retraction facilitates epilaryngeal constriction (Moisik, 2013:26) and consequently occurs often with pharyngeal consonants. Because of this, the most retracted vowel, [a], can be thought of as the most articulatorily similar to pharyngeals.

The effects that post-velar consonants have on vowels constitute important evidence both for the existence of the guttural natural class and for the articulations of the post-velar consonants. Framing this interaction in terms of the features $[ \pm$ back $]$ and $[ \pm$ low $]$ yields little information on the articulation of postvelar consonants since these vocalic features are best interpreted in acoustic terms. However, with a more accurate description of vowel articulation, it is possible to relate the effects that post-velar consonants have on vowels to their articulation in a more precise way.

Typological data show how the post-velar consonants affect vowels in various languages. These data come from a new, large-scale cross-linguistic survey of the post-velar consonants and how they interact in sound patterns (Sylak-Glassman in prep). In Figure 4 below, data for the effects of uvulars come from 10 languages where these effects could be isolated from those of other consonants. For pharyngeals, data come from just 2 languages (Egyptian Arabic and Kabardian) since these were the only languages in which the effects of pharyngeals were described separately from the effects of other post-velar consonants. Data for the effects of all post-velar consonants when they act as a phonological class come from 9 languages.

\footnotetext{
${ }^{9}$ These were not originally proposed as phonological features by Esling (2005), and are interpreted as gross physiological states by Moisik (2013).

${ }^{10}$ This was, of course, done under the same assumption for the traditional vowel features, which were originally regarded as articulatory. Using the traditional features this way helped to highlight their better fit with acoustics.
} 

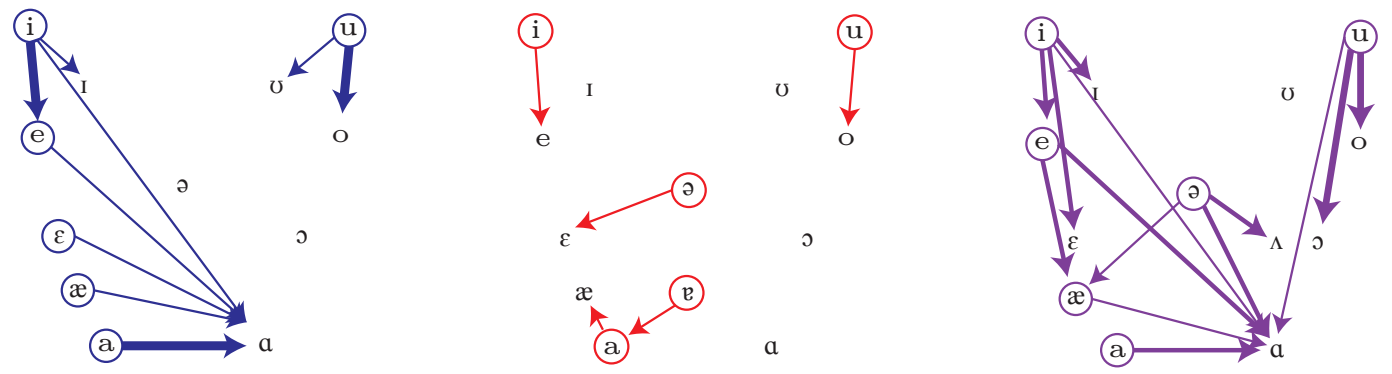

Figure 4: The effects on vowels of uvulars (left), pharyngeals (center), and any post-velar consonants acting as a phonological class (right) based on data in Sylak-Glassman (in prep). Circled vowels undergo effects, and the boldness of arrows indicates the number of languages, from 1-5, in which the effect occurs.

From these data, it is clear that uvulars and pharyngeals both cause vowels to be articulated with a more open vocal tract configuration. This can be seen as the lowering effect commonly described for post-velar consonants, which is also apparent in the data from post-velars acting as a class. Different effects seem to obtain for [+low] vowels. With uvulars, these vowels become more retracted, but with pharyngeals, they can front. ${ }^{11,12}$ With post-velars acting as a class, the non-high vowels generally become more open and retracted, although there is one case of fronting (with [ə] going to [æ] in Tamashek Berber; Heath 2005:35).

\section{Formalizing Pharyngeal Association Effects}

It has been shown that evidence for the guttural natural class is more common in languages with pharyngeals, contra the hypothesis that all post-velar segments are equally likely to participate in processes that provide evidence for the guttural natural class. Pharyngeal consonants are articulatorily linked to the uvulars and glottals. Moreover, the acoustic effects of uvulars on vowels shift those vowels to using articulations associated with pharyngeal consonants, providing yet another link between pharyngeals and uvulars.

Formalizing the ways in which segments become associated with pharyngeals demonstrates how class behavior can be derived. ${ }^{13}$ This study formalizes the effects of post-velar consonants on vowels in Optimality Theory (Prince \& Smolensky, 1993) using similarity scales, which group vowels in terms of both articulatory and acoustic features. Constraints can then refer to steps on these similarity scales, and effects can be derived by satisfying simple markedness constraints.

5.1 Similarity Scales The effects of post-velar consonants on vowels have been taken to provide information on the articulation of post-velars because it has been assumed that these effects are assimilatory. To explain these cross-linguistic effects on vowels in terms of assimilation, vowels need to be related to postvelar consonants in terms of explicit similarity rankings. These can be formulated as scales that reference both articulatory and acoustic features.

The similarity scales presented in Table 3 are constructed with reference to phonetic information (both articulatory and acoustic) and typological data on the effects of post-velar consonants on vowels that were found in the cross-linguistic survey in Sylak-Glassman (in prep). ${ }^{14}$ For each table, the vowel that shares the most articulatory and acoustic properties with a given post-velar consonant is ranked at the top as Step 1. Vowels are then arranged into groups that constitute the rest of the steps in the scale. These groups are formed

\footnotetext{
${ }^{11} \mathrm{John}$ McCarthy (p.c.) points out that the default realization of Egyptian Arabic /a/ may be front [a] rather than central [e], as described by Watson (2002:272). If this is the case, then the pharyngeal consonant does not actively front the vowel, but it does prevent retraction or backing of the vowel.

${ }^{12}$ Moisik (2013:317-325; p.c.) notes that the extreme "double-bunching" articulation of pharyngeal consonants and pharyngealized vowels produces an anterior constriction near the hard palate, which may explain instances of vowel fronting. This "double-bunching" articulation is similar to simultaneous anterior and pharyngeal constrictions found in the bunched articulation of American English /./.

${ }^{13}$ The formalization of direct articulatory connections is not attempted here, but see Moisik (2013).

${ }^{14}$ In principle, acoustic and articulatory similarity could be separated, with the possibility of interleaving them in language-specific ways.
} 
with respect to features that are shared with the vowel that is most similar to consonants at the given postvelar place of articulation. These steps are followed by others with features that do not share articulations with consonants at that place, but do not interfere with their articulation. These steps are in turn followed by others with articulations that are (to various degrees) antithetical or antagonistic to those of the consonants at the given place of articulation.

The uvular consonants are articulated by the tongue dorsum going to a raised position with an overall more open vocal tract configuration. Thus, the vowels that are [+raised, -high], $/ v, \mathrm{o} /$, are most similar to the uvulars as a whole. ${ }^{15}$ The next most similar is the [+raised, +high] vowel, /u/. This is followed by the [+back] vowels (which acoustically select both the [+raised] and [+retracted] vowels). Next come the [+open] vowels, which do not share any articulators with the uvulars, but also do not interfere with their production. After this are groups of vowels whose articulation is in some way antithetical to that of the uvulars. First are the [+front] vowels, followed by the [+front] and [-open] vowels. Based on typological evidence, the vowel that is least similar to the uvulars is /i/. Its dissimilarity to uvulars makes it both a frequent target of local assimilation (being lowered in languages like Huallaga Quechua; Weber 1989) and a blocker of long-distance assimilation (as in San'ani Arabic; Watson 2002:280).

Pharyngeal consonants must be articulated with constriction in the epilarynx, and are often also articulated with an open vocal tract configuration and tongue retraction. Thus, the most similar vowel to pharyngeal consonants from a broad typological perspective is /a/, which is [+open, +retracted, +low]. The next most similar are open vowels with tongue retraction, followed by non-front open vowels, followed by open vowels in general. The [+open, +front] vowels can be antagonistic to tongue retraction, leading to distributional constraints such as the lack of front or high vowels before a coda pharyngeal in Ditidaht (Wakashan; Sylak-Glassman 2013). However, the "double bunching" articulation of pharyngeals in fact involves a [+front] lingual constriction along with tongue retraction and epilaryngeal constriction (Moisik, 2013:482-500). In certain Nakh-Daghestanian languages, such as Avar (Charachidzé, 1981:17), the back vowels are fronted adjacent to pharyngeals, such that $/ \mathrm{u} / \rightarrow[\mathrm{y}]$ and $/ \mathrm{o} / \rightarrow[\varnothing]$. The "double bunching" articulation of pharyngeals is cross-linguistically rare. Thus, the [+front] vowels are usually antagonistic to pharyngeal articulations. No matter the specific articulation of pharyngeals, close, high vowels are the least similar to pharyngeals, with /i/ again the least similar overall.

\begin{tabular}{|c|c|c|}
\hline Step & Features & Vowels \\
\hline 1 & +raised, -high & $\mho, \mathrm{o}$ \\
\hline 2 & +raised, +high & $\mathrm{u}$ \\
\hline 3 & +back & $\mathrm{u}, \mho, \mathrm{o}, \mathrm{\jmath}, \mathrm{a}$ \\
\hline 4 & topen & $\varepsilon, æ, a, e, a, \supset$ \\
\hline 5 & +open, +front & $\varepsilon, æ, \mathrm{a}$ \\
\hline 6 & + front & $\mathrm{i}, \mathrm{I}, \mathrm{e}, \varepsilon, æ, \mathrm{a}$ \\
\hline 7 & +front, -open & $\mathrm{i}, \mathrm{I}, \mathrm{e}$ \\
\hline 8 & +front, -open, +high & $\mathrm{i}$ \\
\hline
\end{tabular}

\begin{tabular}{|c|c|c|}
\hline \multirow[b]{2}{*}{ Step } & \multicolumn{2}{|c|}{ Similarity to Pharyngeals } \\
\hline & Features & Vowels \\
\hline 1 & +open, +retracted, +low & a \\
\hline 2 & +open, +retracted & $\mathrm{a}, \mathrm{J}$ \\
\hline 3 & +open, -front & $e, a, j$ \\
\hline 4 & topen & $\varepsilon, æ, a, e, a, \supset$ \\
\hline 5 & +open, +front & $\varepsilon, \mathfrak{a}, \mathrm{a}$ \\
\hline 6 & + front & $\mathrm{i}, \mathrm{I}, \mathrm{e}, \varepsilon, æ, \mathrm{a}$ \\
\hline 7 & -open & $\mathrm{i}, \mathrm{I}, \mathrm{e}, \mathrm{o}, v, \mathrm{u}$ \\
\hline 8 & + front, -open & $\mathrm{i}, \mathrm{I}, \mathrm{e}$ \\
\hline 9 & -open, +high & $\mathrm{i}, \mathrm{u}$ \\
\hline 10 & +front, -open, +high & $\mathrm{i}$ \\
\hline
\end{tabular}

Table 3: Scales of similarity of vowels to uvulars (left) and pharyngeals (right).

5.2 Effects on Vowels in Terms of Similarity Scales The cross-linguistic effects that post-velars have on vowels, shown in Figure 4, can now be described in terms of the similarity scales in Table 3. In general, the effects of post-velars on vowels are assimilatory and involve a change in which a vowel in contact with a post-velar consonant changes to move up the similarity scale. For example, in contact with uvulars, /u/, a Step 2 vowel, often becomes [ $\mho]$ or [o]. In the same environment, the vowel /i/ moves up the similarity scale from Step 8 to Step 6 or 7 . In both these changes, /i/ and /u/ become open to accommodate the more open

\footnotetext{
${ }^{15}$ Because the tongue dorsum is higher with uvular stops than with uvular fricatives, uvular stops and fricatives differ slightly in which vowel they are most similar to, i.e. uvular stops may be more similar to / / / than /o/ while the reverse may be true for uvular fricatives.
} 
articulations of the post-velar consonants. ${ }^{16}$

When pharyngeals act as part of a phonologically active class composed of post-velars, as in the rightmost vowel movement chart in Figure 4, their effects on vowels are similar to those of uvulars in that vowels assimilate and move up the similarity scale. However, their effects on vowels are best interpreted as dissimilatory when they cause different effects than uvulars, as in Egyptian Arabic and Kabardian, from which the data for the middle vowel movement chart in Figure 4 come. These effects are dissimilatory because they move vowels down the similarity scale, for example, from Step 3 to Step 5. In these two languages, in which the effects of pharyngeals differ from the effects of uvulars, non-high vowels front. Because lingual movement plays only an enhancing role for pharyngeals while for uvulars, it is obligatory, vowels becoming [+back] (articulatorily either raised or retracted) in the context of uvulars almost always occurs. However, with pharyngeals, vowels can be fronted without affecting the articulation of the consonant. The fact that this is true is proven by the possibility of the double-bunching articulation for pharyngeals. Therefore, vowel fronting is a means by which the effects on vowels of pharyngeals can be differentiated from the effects of uvulars. Differentiating the effects of these consonants may increase their perceptibility, and in this sense, the fronting of vowels in the context of pharyngeals can be seen as an available, but not obligatory, phonetic enhancement (Stevens et al., 1986).

The similarity scales proposed here, like those in Mortensen (2006) and Lionnet (2013), exist independently of Optimality Theory constraints. However, unlike the scales in Mortensen (2006), the similarity scales proposed here are explicitly meant to capture aspects of phonetic substance, rather than being purely logical. Another approach to capturing similarity is relating segments through entailments as in Wayment (2009). Highly specific entailments, which relate one feature to another on the basis of the cooccurrence of features within a segment, allow a more nuanced approach to defining segmental similarity that can incorporate phonetic subfeatures, which are fundamental to explanations in Moisik (2013) and Lionnet (2013). Wayment's use of ATTRACT and CORR constraints to define similarity in terms of both substance and string-level proximity also allow very precise modeling of assimilation processes.

5.3 Preliminary Analysis To derive the effects of post-velar consonants on vowels, constraints are able to refer to the steps of the similarity scales for consonants at post-velar places of articulation. Markedness constraints militate against post-velar consonants occurring with vowels at certain steps of the appropriate similarity scale. The markedness constraints are defined schematically in (1).

*CV Step \#

Assign one violation mark for each pairing of a consonant, C, with a vowel, V, which is in Step \# of C's similarity scale and in the same syllable.

This definition is for the purposes of illustration and could be changed to accommodate various locality restrictions between the consonant and vowel. Note that the extent to which the vowel violates the constraint is unimportant for formal evaluation: Any violation counts as a single formal violation. These constraints are ranked above input-output identity constraints, whose low ranking promotes violation. The specific featural changes that occur as a result of violating these IDENT constraints are the repairs that allow satisfaction of the $* \mathrm{CV}_{\text {Step \# }}$ constraints.

To illustrate the use of these constraints, data from Cairene Arabic and Jaqaru (Jaqi) will be used. Each example shows assimilation of vowels that are not similar enough to the neighboring post-velar consonant. In Cairene Arabic, before a pharyngeal consonant in coda position, short /i/ is realized as $[\varepsilon]$, short $/ \mathrm{u} /$ is realized as [o], and short $/ \mathfrak{l} /$ is realized as the low front vowel [a] (Watson, 2002:271-272). ${ }^{17}$ The tableau in (2) illustrates how to derive these effects using a hypothetical input. In the markedness constraints, U stands for 'uvular' and $\mathrm{P}$ for 'pharyngeal.' These abbreviations stand in for a featural representation here.

\footnotetext{
${ }^{16}$ This is difficult to formalize using descriptive features rather than relational or integer-valued features. In contact with uvulars or pharyngeals, vowels typically go down one level in terms of height (or aperture) to [e, o], for example. The fact that cross-linguistically, vowels often go down one degree in terms of height rather than assimilating to a specific vowel quality (such that [i] and [e] both consistently go to $[\varepsilon]$, for example, cross-linguistically) makes a relational description more natural.

${ }^{17}$ This description of the data is true, but describes only the simplest locality restrictions for the purpose of illustration. In reality, /u/ becomes [o] "[w]hen tautosyllabic with a pharyngeal" and / $\mathrm{e} /$ is realized as low front [a] "[a]djacent to the pharyngeals" (Watson, 2002:271-272). Recall that the fronting of /a/ may be an enhancement effect, not assimilation.
} 
(2)

\begin{tabular}{|c|c|c|c|c|c|c|}
\hline & /tiSbuYteS/ & $* \mathrm{PV}_{\text {Step } 3}$ & $\mathrm{PV}_{\text {Step } 9}$ & IDENT[high] & IDENT[front] & IDENTV \\
\hline & tiSbuites & 1 & $2 !$ & & 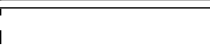 & \\
\hline & tefbuStef & 1 & $1 !$ & 1 & & 1 \\
\hline & tefboftef & $1 !$ & + & 2 & & 2 \\
\hline$\rightarrow$ & tefboftaf & & 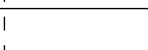 & 2 & 1 & 3 \\
\hline
\end{tabular}

In Jaqaru (Jaqi), adjacent to uvulars, $/ \mathrm{i} /$ is realized as $[\varepsilon], / \mathrm{u} /$ is realized as $[\mathrm{o}]$, and $/ \mathrm{a} /$ is realized as $[\mathrm{a}]$ (Hardman, 1983:42, 83). These effects are illustrated in (3) using a hypothetical input.

\begin{tabular}{|c||c:c:c|c:c|c|}
\hline /qiquqa/ & $* \mathrm{UV}_{\text {Step 2 }}$ & $* \mathrm{UV}_{\text {Step } 5}$ & $* \mathrm{UV}_{\text {Step } 8}$ & IDENT[high] & IDENT[front] & IDENTV \\
\hline \hline qiquqa & 1 & 1 & $1 !$ & & & \\
\hline qequqa & 1 & $1 !$ & & 1 & & \\
\hline qeqoqa & & $1 !$ & & 2 & & 1 \\
\hline qeqoqa & & & & 2 & 1 & 3 \\
\hline
\end{tabular}

These examples show how segments can pattern together as phonological classes. Both Cairene Arabic and Jaqaru have subsets of vowels that are marked in a certain environment. In a given language, if the post-velar consonants (or a subset of them) condition the same changes on a set of vowels, then, following Flemming (2005), the set of vowels forms a phonological class because the vowels share the same violation profile with respect to the constraints in the derivation. However, the post-velar consonants that condition the violations are also a phonological class. The similarity scales in these derivations provide sets of vowels that constraints can refer to, but this recapitulates the function of the features that define the steps in the scales. The more important function of the similarity scales is to incorporate phonetic explanations for why the postvelars affect vowels by formally defining similarity. This makes it possible to determine whether the effects of post-velars on vowels are assimilatory or dissimilatory.

\section{Conclusion}

This paper has argued that the predictions that arise from the claim that the guttural natural class is part of humans' innate knowledge of language are not borne out by typological data. Most importantly, the prediction that all post-velar consonants should be equally likely to exhibit evidence of the existence of the guttural natural class is not borne out. Languages with pharyngeals are more likely to exhibit such evidence than languages lacking pharyngeals, including even languages that have consonants at both other post-velar places of articulation (uvular and glottal). This is interpreted as evidence that the pharyngeals are able to pull other consonants into patterning together with them. Such phonological association could occur with consonants at other places of articulation, which, for phonetic reasons, become associated with other consonants in phonological processes for phonetic reasons. A possible group of sounds whose patterning may be explained by phonological association is the rhotics, which share articulatory and acoustic similarities when compared as individual pairs, but share none when considered as an entire class.

Both articulatory and acoustic properties play a role in the effects of post-velar consonants on vowels. These effects can be formalized using constraints that refer to similarity scales, which relate vowels to postvelar consonants in terms of both articulatory and acoustic phonological features. In doing so, they provide a formal means of defining similarity for the purpose of determining whether the effects of post-velars are assimilatory or dissimilatory and to what degree.

The guttural natural class, rather than being innate, emerges in specific languages from phonological processes and distributional constraints that are conditioned by phonetic properties. The emergence of the guttural natural class can occur formally through mechanisms identified by Flemming (2005). Postvelar consonants can share the same constraint violation profile in an Optimality Theoretic derivation or can be referred to together by one or more constraints. Through these mechanisms, groups of post-velar consonants can be established as a phonologically active class, in the definition of Mielke (2008:13). When these groupings can be explained on phonetic grounds, they constitute a phonetically natural class (again, in the definition of Mielke 2008:12). Instead of the guttural natural class being innate and possibly universal as a single, pre-ordained phonological entity, phonological classes that involve diverse sets of post-velar consonants emerge in particular languages from phonological patterns that often have phonetic explanations. 


\section{References}

Bessell, Nicola J. (1992). Towards a Phonetic and Phonological Typology of Post-Velar Articulation. Ph.D. thesis, University of British Columbia, Vancouver, BC.

Charachidzé, Georges (1981). Grammaire de la langue avar. Éditions Jean-Favard, Paris.

Esling, John H. (1997). Pharyngeal approximants, fricatives, trills, and stops. Working Papers of the Linguistics Circle of the University of Victoria 14, 1-12.

Esling, John H. (2005). There are no back vowels: The laryngeal articulator model. The Canadian Journal of Linguistics 50:1, 13-44.

Flemming, Edward (2005). Deriving natural classes in phonology. Lingua 115, 287-309.

Goldstein, Louis (1994). Possible articulatory bases for the class of guttural consonants. Keating, Patricia A. (ed.), Phonological Structure and Phonetic Form, Papers in Laboratory Phonology III, Cambridge University Press, Cambridge, UK, 234-241.

Hardman, Martha J. (1983). Jaqaru. Instituto de Estudios Peruanos, Lima, Perú.

Hayward, K. M. \& Richard J. Hayward (1989). 'Guttural': Arguments for a new distinctive feature. Transactions of the Philological Society 87:2, 179-193.

Heap, Lynn M. (1997). Acoustic analysis of pharyngeal approximants, fricatives, trills, and stops. Working Papers of the Linguistics Circle of the University of Victoria 13-22.

Heath, Jeffrey (2005). A Grammar of Tamashek (Tuareg of Mali). Mouton de Gruyter, Berlin.

Jakobson, Roman (1962). Mufaxxama: The 'emphatic' phonemes in Arabic. Jakobson, Roman (ed.), Phonological Studies, Mouton and Co., The Hague, vol. 1 of Selected Writings, 510-522.

Ladefoged, Peter \& Ian Maddieson (1996). Sounds of the World's Languages. Blackwell, Oxford, UK.

Lewis, M. Paul (2009). Ethnologue: Languages of the World. SIL International, Dallas, TX. Online version: http://www.ethnologue.com/.

Lionnet, Florian (2013). Doubly triggered harmony in Laal as subphonemic Agreement by Correspondence. Handout from poster presented at Phonology 2013 at the University of Massachusetts, Amherst.

McCarthy, John J. (1991). Semitic gutturals and distinctive feature theory. Comrie, Bernard \& Mushira Eid (eds.), Perspectives on Arabic Linguistics III: Papers from the Third Annual Symposium on Arabic Linguistics, John Benjamins, Philadelphia, 63-91.

McCarthy, John J. (1994). The phonetics and phonology of Semitic pharyngeals. Keating, Patricia A. (ed.), Phonological Structure and Phonetic Form, Papers in Laboratory Phonology III, Cambridge University Press, Cambridge, UK, 191-233.

Mielke, Jeff (2008). The Emergence of Distinctive Features. Oxford University Press, Oxford. P-base accessed via http://137.122.133.199/ Jeff/pbase/.

Moisik, Scott (2013). The Epilarynx in Speech. Ph.D. thesis, University of Victoria, Victoria, BC.

Mortensen, David R. (2006). Logical and Substantive Scales in Phonology. Ph.D. thesis, University of California, Berkeley, Berkeley, CA.

Prince, Alan \& Paul Smolensky (1993). Optimality Theory: Constraint interaction in generative grammar. Ms., Rutgers University and University of Colorado, Boulder. RuCCS-TR-2. ROA 537-0802.

R Core Team (2013). R: A Language and Environment for Statistical Computing. R Foundation for Statistical Computing, Vienna, Austria, URL http: / / www.R-project.org.

Rose, Sharon (1996). Variable laryngeals and vowel lowering. Phonology 13, 73-117.

Schulze, Wolfgang (2000). Northern Talysh. Lincom Europa, Munich.

Stevens, Kenneth, Samuel J. Keyser \& Haruko Kawasaki (1986). Toward a phonetic and phonological theory of redundant features. Perkell, Joseph S. \& Dennis H. Klatt (eds.), Invariance and Variability in Speech Processes, Erlbaum, Hillsdale, NJ, 426-449.

Sylak-Glassman, John (2013). The effects of post-velar consonants on vowels in Ditidaht. Paper presented at the 48th International Conference on Salish and Neighbouring Languages (ICSNL). Victoria, BC.

Sylak-Glassman, John (In prep). Defining Natural Classes: The Phonology and Typology of Post-Velar Consonants. Ph.D. thesis, University of California, Berkeley, Berkeley, CA.

Watson, Janet C. E. (2002). The Phonology and Morphology of Arabic. Oxford University Press.

Wayment, Adam (2009). Assimilation as Attraction: Computing Distance, Similarity, and Locality in Phonology. Ph.D. thesis, Johns Hopkins University, Baltimore, MD.

Weber, David J. (1989). A Grammar of Huallaga (Huánuco) Quechua, vol. 112 of University of California Publications in Linguistics. University of California Press, Berkeley, CA.

Zawaydeh, Bushra Adan (2003). The interaction of the phonetics and phonology of gutturals. Local, John, Richard Ogden \& Rosalind Temple (eds.), Phonetic Interpretation: Papers in Laboratory Phonology VI, Cambridge University Press, New York, 279-292. 